\title{
Reverse transformation of deformation-induced martensite in austenitic stainless steel studied by positron annihilation
}

\author{
E. Dryzek • M. Sarnek $\cdot$ M. Wróbel
}

Received: 7 May 2014/Accepted: 17 August 2014/Published online: 28 August 2014

(c) The Author(s) 2014. This article is published with open access at Springerlink.com

\begin{abstract}
The reversion of deformation-induced $\alpha^{\prime}$-martensite in tension-deformed $1.4301(\mathrm{EN})$ stainless steel was investigated using positron annihilation spectroscopy. The Doppler broadening of the annihilation line and positron lifetime spectroscopy were applied to study defect structure and its annealing behavior in samples with a similar deformation level but varying in $\alpha^{\prime}$-martensite amount. The difference in $\alpha^{\prime}$-martensite was obtained by applying different deformation temperatures, i.e., liquid nitrogen temperature, room temperature, and $200{ }^{\circ} \mathrm{C}$. The cumulative annealing of the tension-deformed samples and measurement of the positron annihilation characteristics show the gradual annealing of defects in the temperature range between 200 and $400{ }^{\circ} \mathrm{C}$ due to the recovery and recrystallization. However, in the temperature range between 450 and $650{ }^{\circ} \mathrm{C}$, the generation of vacancy clusters which trap positrons is revealed. This temperature range coincides with the temperature range of $\alpha^{\prime}$-martensite reversion which is confirmed by microhardness and magnetization measurements. The detected large vacancy clusters consisting of 6-9 vacancies can occur at the interface between austenite and $\alpha^{\prime}$-martensite phases due to the volume contraction accompanying bcc/fcc change.
\end{abstract}

\footnotetext{
E. Dryzek $(\bowtie) \cdot$ M. Sarnek

Institute of Nuclear Physics PAN, ul. Radzikowskiego 152,

31-342, Kraków, Poland

e-mail: ewa.dryzek@ifj.edu.pl

M. Sarnek

e-mail: maciej.sarnek@ifj.edu.pl

M. Wróbel

AGH University of Science and Technology, 30 Av.

Mickiewicza, 30-059 Kraków, Poland

e-mail: mwrobel@agh.edu.pl
}

\section{Introduction}

Martensitic transformation induced by plastic deformation of metastable austenitic stainless steel (SS) is a well-known phenomenon $[1,2]$ depending on steel composition and deformation conditions, e.g., temperature, strain rate, and state. Deformation-induced martensite (DIM) changes important properties of steel, e.g., the strain-hardening coefficient and formability. During plastic deformation (briefly, deformation) of metastable austenitic SS, ع-martensite with hexagonal close-packed crystal structure and $\alpha^{\prime}$-martensite with body-centered cubic crystal structure can be formed. Whereas austenite ( $\gamma$ phase) and $\varepsilon$-martensite are paramagnetic, $\alpha^{\prime}$-martensite is ferromagnetic. Then changes in magnetic properties of SS due to the formation of $\alpha^{\prime}$-martensite can be used for its detection [35]. It was found that in a low deformation range more $\varepsilon$ martensite than the $\alpha^{\prime}$-martensite is formed [6]. The amount of $\alpha^{\prime}$-martensite significantly grows with deformation and following transformation sequences $\gamma \rightarrow \varepsilon \rightarrow \alpha^{\prime}$ and $\gamma \rightarrow \alpha^{\prime}$ have been reported [7, 8]. The former is typical for steels with low stacking fault energy (SFE), the latter for steels for somewhat higher SFE [9]. In addition to the plastic strain, strain rate and the SFE of material related to the material chemistry and temperature, the DIM amount also depends on grain size and orientation [10-13].

Metastable austenitic SS is strengthened by dislocation structure and DIM formation during cold working [14]. In some cases, DIM can also have unfavorable effects such as the delayed cracking phenomenon of deep-drawn austenitic SS components [15]. Also the change of magnetic properties related to martensitic transformation is not acceptable for some applications [16]. Therefore, martensitic transformation in metastable austenitic SSs has been 
extensively studied mainly for practical reasons [17-19]. On the other hand, details of the DIM transformations during aging of the deformed metastable austenitic SS are less known. The aging can lead to additional formation of $\alpha^{\prime}$-martensite [20] and to reverse transformation of DIM, i.e., $\alpha^{\prime} \rightarrow \gamma$. The reversion of $\varepsilon$ and $\alpha^{\prime}$-martensite occurs in temperature ranges $150-400$ and $400-850{ }^{\circ} \mathrm{C}$, respectively [4, 21-23]. However, there have been reports that reversion $\alpha^{\prime} \rightarrow \gamma$ occurs at $500-600{ }^{\circ} \mathrm{C}$ and at about $570-850{ }^{\circ} \mathrm{C}$ [9]. A crystallographic and kinetic basis for the thermal reversibility of the martensitic transformations comes from the thermoelastic behavior of martensites described by Kurdyumov and Khandros [24]. The reverse transformation results in formation of austenite with high dislocation density [25], micro-twins, and stacking faults [26, 27]. Inducing martensitic transformation in metastable martensitic SS and then reverting the martensite to austenite through aging has been found to be a workable option for grain refinement in order to increase yield strength without impairing ductility of the material [28, 29].

A variety of experimental methods have been applied to study both martensitic transformation and DIM reversion in SSs, e.g., microscopic methods, X-ray diffraction, magnetic or mechanical properties measurements. Positron annihilation spectroscopy (PAS) is used for SS studies as well; however, no studies of DIM reversion have been performed. The PAS techniques are well-known experimental methods used for the study of defects in crystalline matter [30]. Positrons (antimatter particles) implanted into a metallic system annihilate with electrons emitting gamma ray photons. These photons contain useful information on the electron momentum distribution in the sites where the annihilation takes place. As the distribution is different for perfect crystal lattice and lattice defects this is reflected in the Doppler broadening (DB) of the positron annihilation line characterized by the line shape parameters such as the S-parameter. The positron lifetime, i.e., the time between emission of positrons from a radioactive source and detection of annihilation photons depends on electron density. It is higher for positrons trapped in open volume defects i.e., vacancies, vacancy agglomerates and dislocations than for positrons in a perfect crystal lattice. PAS can be used for identification and tracking of changes of crystal lattice defects, i.e., their generation during deformation or their annealing. These techniques have been successfully used for non-destructive evaluation of fatigue damage in SSs [31-33] and detection of the subsurface zone defects created by sliding, cutting [34, 35], or shot peening [36]. PAS was applied to determine vacancy migration energy in SS [37, 38]. Sensitivity of PAS is sufficient for investigation of the phase transformations in different materials $[39,40]$, and this technique has been profitably applied in microstructural characterization of steels which are candidates for structural materials in nuclear facilities [41, 42].

Our preliminary experiments have shown that reverse transformation of DIM in metastable austenitic SSs can be investigated using DB of the annihilation line. PAS measurements have revealed two processes which take place during annealing of deformed SS containing DIM, i.e., migration and sinking of vacancies and creation of additional lattice defects accompanying $\alpha^{\prime}$-martensite reversion to austenite $[43,44]$. The aim of the study was application of this technique to investigation of annealing behavior of SS 1.4301 (EN) deformed in tension at different temperatures. Different deformation temperatures allowed us to obtain different amount of $\alpha^{\prime}$-martensite for the samples with similar level of deformation. Samples were also investigated using XRD, and their microhardness and magnetic properties were measured.

\section{Experimental details}

\section{Sample preparation}

The steel studied was Polish commercial SS 1.4307 (EN) which is equivalent to AISI Grade 304 SS. The specimens of dimensions $15 \times 3 \times 100 \mathrm{~mm}^{3}$ were cut from a flat bar and subjected to solution annealing at $1100{ }^{\circ} \mathrm{C}$ for $30 \mathrm{~min}$ followed by quenching in air. After heat treatment, surface of the samples was etched using hydrochloric acid and nitric acid water solution. The chemical composition of the steel was determined using a glow discharge atomic emission spectrometer LECO GDS 850A. Carbon content was measured by an infrared absorption after combustion in an induction furnace using LECO CS600 analyzer, and nitrogen content was determined using LECO TCH 660 analyzer. Table 1 shows the chemical composition of the steel studied.

The plastic deformation was performed in uniaxial tension using the MTS- 810 testing machine at three different temperatures, i.e., liquid nitrogen $\left(\mathrm{LN}_{2}\right)$ temperature, room temperature (RT), and $200{ }^{\circ} \mathrm{C}$ to obtain three samples with similar level of strain i.e., $A(\varepsilon=5 \%), B(\varepsilon=6 \%)$, and $C(\varepsilon=9 \%)$ and different amounts of deformationinduced $\alpha^{\prime}$-martensite. For comparison, the forth sample was deformed to much higher strain $D(\varepsilon=32 \%)$ at RT. The deformation conditions are given in Table 2 . Three specimens of length of $15 \mathrm{~mm}$ were cut from adjacent places of the deformed samples (the gage length was $80 \mathrm{~mm}$ ). Two of them were used for positron annihilation measurements, i.e., DB of the annihilation line and the positron lifetime. The third was used for measurements of microhardness and the relative change in magnetization. The samples were subjected to cumulative isochronal 
Table 1 Steel composition $(\mathrm{wt} \%)$

\begin{tabular}{lllllllllll}
\hline $\mathrm{Cr}$ & $\mathrm{Ni}$ & $\mathrm{Mn}$ & $\mathrm{Si}$ & $\mathrm{Cu}$ & $\mathrm{Mo}$ & $\mathrm{V}$ & $\mathrm{P}$ & $\mathrm{S}$ & $\mathrm{C}$ & $\mathrm{N}$ \\
\hline 18.00 & 8.10 & 1.46 & 0.40 & 0.26 & 0.10 & 0.09 & 0.033 & 0.005 & 0.023 & 0.05 \\
\hline
\end{tabular}

Table 2 The deformation conditions, magnetization per unite mass $\sigma_{\mathrm{s}}$, and volume fraction of $\alpha^{\prime}$-martensite $f_{\alpha^{\prime}}$ of the tension-deformed samples

\begin{tabular}{lclcc}
\hline Sample & $\begin{array}{l}\text { Tensile } \\
\text { strain } \varepsilon\end{array}$ & $\begin{array}{l}\text { Deformation } \\
\text { temperature }\end{array}$ & $\begin{array}{l}\sigma_{\mathrm{s}} \\
(\mathrm{emu} / \mathrm{g})\end{array}$ & $f_{\alpha^{\prime}}$ \\
\hline$A$ & $5 \%$ & $\mathrm{LN}_{2}$ & 39.49 & 0.25 \\
$B$ & $6 \%$ & $\mathrm{RT}$ & 6.02 & 0.04 \\
$C$ & $9 \%$ & $200{ }^{\circ} \mathrm{C}$ & 3.99 & 0.03 \\
$D$ & $32 \%$ & $\mathrm{RT}$ & 29.62 & 0.19 \\
\hline
\end{tabular}

$R T$ room temperature, $L N_{2}$ liquid nitrogen temperature

annealing in the flow of $\mathrm{N}_{2}$ gas for $1 \mathrm{~h}$ at temperatures range from 50 to $800{ }^{\circ} \mathrm{C}$ with temperature step of $25^{\circ} \mathrm{C}$. After $1 \mathrm{~h}$-annealing at a given temperature, the samples were etched in order to remove the oxidized surface layer, and the positron annihilation, magnetization change, and microhardness were measured.

\section{Magnetic properties measurements}

Magnetic properties of the samples were characterized by two methods. Response of the deformed samples to magnetic field was determined using the MPMS SQUID magnetometer. Magnetization curves up to $10 \mathrm{kOe}$ were measured at room temperature for additional samples of dimensions ca. $2 \times 2 \times 3 \mathrm{~mm}^{3}$ cut using the low speed diamond wheel saw and etched to remove the layer deformed by cutting. The volume fraction of $\alpha^{\prime}$-martensite $f_{\alpha^{\prime}}$ induced by plastic deformation was calculated by the formula proposed by Mangonon and Thomas: $f_{\alpha^{\prime}}=\sigma_{\mathrm{s}}$ ' 160.4 , where $\sigma_{\mathrm{s}}$ is specific saturation magnetization per unit mass [2]. Relative changes in magnetization induced by annealing of the deformed samples were determined by other measurements according to the method described by Davis $[45,46]$. The magnetization measured by the magnetic balance is given in arbitrary units. The amount of the $\alpha^{\prime}$-martensite is related to its amount initially present in the as-deformed samples. In these measurements, the maximum magnetic induction used was equal to $20 \mathrm{mT}$.

\section{XRD and microhardness measurements}

The X-ray diffraction measurements were carried out using a Philips X-Pert diffractometer using $\mathrm{Cu} K_{\alpha}$ radiation. The microhardness was measured with the Vickers indenter under 100 gram (HV0.1) using a Zeiss-Neophot 30 microscope.

\section{PAS measurements}

For the positron annihilation measurements, the ${ }^{22} \mathrm{Na}$ isotope positron source enveloped in a $7-\mu \mathrm{m}$-thick kapton foil was used. The applied Doppler broadening (DB) spectrometer with a coaxial high purity germanium (HPGe) detector (produced in Institute of Nuclear Physics PAN) had the energy resolution equal to $1.4 \mathrm{keV}$ - the full width at half maximum (FWHM) interpolated at $511 \mathrm{keV}$. Other components of the spectrometer were produced by ORTEC. As a result, the dependence of the so-called S-parameter defined as the ratio of the area under the fixed central part of the annihilation line to the area under the whole annihilation line was determined. The S-parameter is sensitive to annihilation of positrons with low momentum electrons which are present in open volume defects. The positron lifetime spectra of more than $1.5 \times 10^{6}$ counts were measured using a fast-fast spectrometer with $\mathrm{BaF}_{2}$ scintillators, Photonis XP2020Q photomultipliers, and other electronic components made by ORTEC. The time resolution of the spectrometer was equal to $280 \mathrm{ps}$ (FWHM). All the obtained spectra were analyzed using the LT-code after subtracting contribution of the positron source and background [47]. Doppler broadening of the annihilation line was measured after each annealing. The positron lifetime measurements were performed for the asdeformed samples and the samples annealed at selected temperatures.

\section{Results}

XRD measurements

X-ray diffraction patterns for the sample after solution annealing and the as-deformed samples are depicted in Fig. 1. For all the samples, the peaks of $\gamma$ and $\alpha^{\prime}$ phases are present. It is visible that the solution annealing and quenching in air did not produce fully austenitic microstructure. Change in relative intensity of picks for both phases clearly shows that amount of $\alpha^{\prime}$-martensite significantly decreases with increasing deformation temperature for the low deformation range (sample sequence $A, B, C$ ). For the sample $A(\varepsilon=5 \%)$ deformed at $\mathrm{LN}_{2}$ temperature $\alpha^{\prime}$-martensite phase dominates. This confirms the results obtained by Herrera et al. who found that amount of the $\alpha^{\prime}$ martensite in 304L SS increases both with deformation level and the temperature lowering from $200{ }^{\circ} \mathrm{C}$ to RT and 


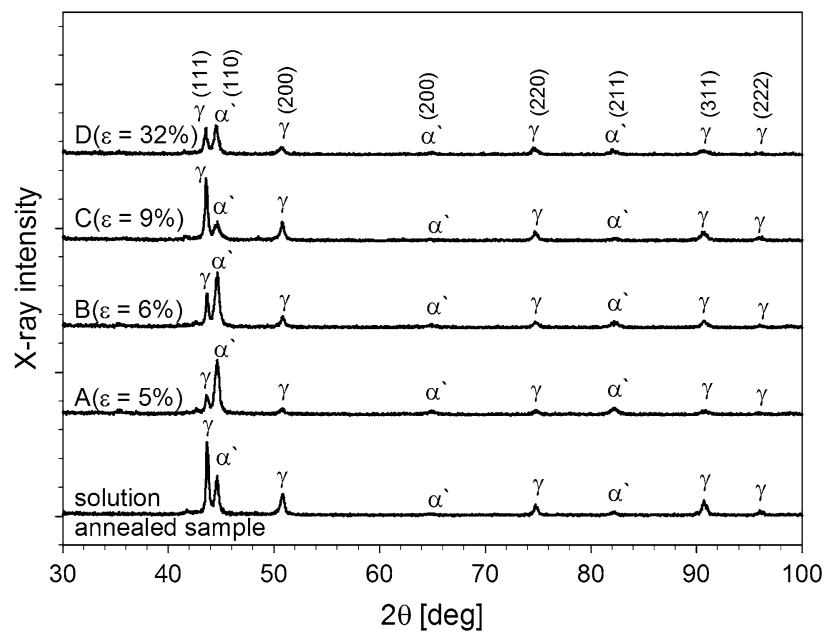

Fig. 1 X-ray diffraction patterns for the sample after solution annealing and for the tension-deformed samples registered along the strain direction

to $-196{ }^{\circ} \mathrm{C}$, and martensite is not detected in the steel deformed in tension at $200{ }^{\circ} \mathrm{C}$ [13]. Significantly lower ratio of $\alpha^{\prime}$ (110) to $\gamma$ (111) reflection intensities for the specimen $D(\varepsilon=32 \%)$ deformed at RT in comparison to that for the specimen $A(\varepsilon=5 \%)$ deformed at $\mathrm{LN}_{2}$ temperature can be related to the crystallographic texture. Differences in texture can be evaluated by comparing intensity ratios of the austenite reflections. For the sample $D(\varepsilon=32 \%)$, the ratio of $\gamma(111)$ to $\gamma(200)$ reflection intensities is equal to 3.3 , while for the remaining deformed samples, it is equal to 2.9-3. For the material without texture it is ca. 2. It is known that crystallographic texture can falsify results of the X-ray phase analysis [48, 49]. Therefore, the magnetic measurements were preformed to obtain the $\alpha^{\prime}$-martensite amount.

\section{Magnetization measurements}

Figure 2 shows the room temperature magnetization curves, and Table 2 presents values of the specific saturation magnetization per unit mass $\sigma_{\mathrm{s}}$ and volume fraction of $\alpha^{\prime}$-martensite $f_{\alpha^{\prime}}$ for the as-deformed samples. The highest amount of $\alpha^{\prime}$-martensite, i.e., 0.25 was obtained for the sample $A(\varepsilon=5 \%)$ deformed at $\mathrm{LN}_{2}$ temperature.

Figure 3 presents the summary of the results obtained using different measurement methods. The relative changes of magnetization as a function of annealing temperature are shown in Fig. 3a. The right axis shows the corresponding values of volume fraction of $\alpha^{\prime}$-martensite $f_{\alpha^{\prime}}$. The values of magnetization are normalized to the initial magnetization for the as-deformed sample $A(\varepsilon=5 \%)$. Up to c.a. $400{ }^{\circ} \mathrm{C}$, the magnetization does not change significantly with temperature. Then. it decreases, which results from the reversion of deformation-induced $\alpha^{\prime}$-martensite and for

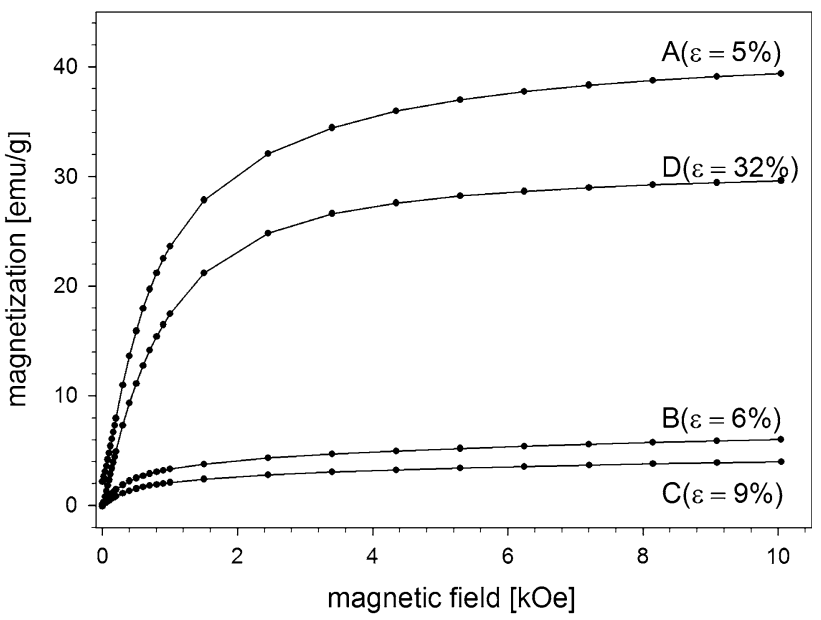

Fig. 2 Magnetization curves for the samples deformed in tension in different conditions to given strains

the samples deformed at RT or at $200{ }^{\circ} \mathrm{C}$, i.e., $B(\varepsilon=6 \%)$, $C(\varepsilon=9 \%)$, and $D(\varepsilon=32 \%)$, it reaches the value close to zero at $700{ }^{\circ} \mathrm{C}$. For the sample $A(\varepsilon=5 \%)$, the magnetization remains higher than for other samples even after annealing at $800{ }^{\circ} \mathrm{C}$, indicating that the reversion is not complete in this case. From Fig. $3 \mathrm{a}$, it is possible to determine the $50 \%$ reversion temperature $\mathrm{T}_{50 \% \mathrm{RM}}$. For the samples $A(\varepsilon=5 \%)$ and $D(\varepsilon=32 \%)$, it is close to $590 \pm 10^{\circ} \mathrm{C}$. The changes of the $\alpha^{\prime}$-martensite amount will be connected to the results obtained using other measurement methods.

\section{Vickers microhardness measurement}

The results of Vickers microhardness measurements as a function of annealing temperature are shown in Fig. $3 b$. The initial value of microhardness is the highest (i.e., 370 HV) for the sample $D(\varepsilon=32 \%)$. For the sample $A(\varepsilon=5 \%)$, it is slightly lower (i.e., $290 \mathrm{HV})$. For the samples $B(\varepsilon=6 \%)$ and $C(\varepsilon=9 \%)$, the initial microhardness values are very close (i.e., $225 \mathrm{HV}$ and 215 $\mathrm{HV})$ as are the magnetization values. The microhardness values do not change significantly up to the annealing temperature of $450{ }^{\circ} \mathrm{C}$. They start decreasing at $500{ }^{\circ} \mathrm{C}$ and for the samples with the low level of deformation they reach the value c.a. $150 \mathrm{HV}$ independently of the initial $\alpha^{\prime}$ martensite fraction. The sample $D(\varepsilon=32 \%)$ has higher final value of the Vickers microhardness (i.e., $190 \mathrm{HV}$ ), but the $\alpha^{\prime}$-martensite amount after annealing for this sample is close to zero as it is for the samples $B(\varepsilon=6 \%)$ and $C(\varepsilon=9 \%)$. Softening of the material coincides with the $\alpha^{\prime}$-martensite reversion in particular for samples with higher amount of $\alpha^{\prime}$-martensite. Further softening may be connected with recovery and recrystallization of the $\gamma$ phase retained regions. Recrystallization of the austenitic 
Fig. 3 Relative changes of magnetization as a function of annealing temperature for the samples deformed by tension in different conditions to given strain levels for $1 \mathrm{~h}$ isochronal annealing. a For samples $A$ and $D$, the solid lines are fitted using sigmoidal function.

Microhardness as a function of annealing temperature. $\mathbf{b}$ The dashed lines are plotted to guide the eye. The S-parameter as a function of annealing temperature. c The smooth solid lines are fitted using the vacancy migration model [37]. The insert presents the mean positron lifetime as a function of annealing temperature. The dashed horizontal straight lines in all parts show the values of the measured quantities for the initial solution annealed sample. The hatched area marks the $\alpha^{\prime}$ martensite reversion temperature range. For magnetization and microhardness, exemplary error bars are shown

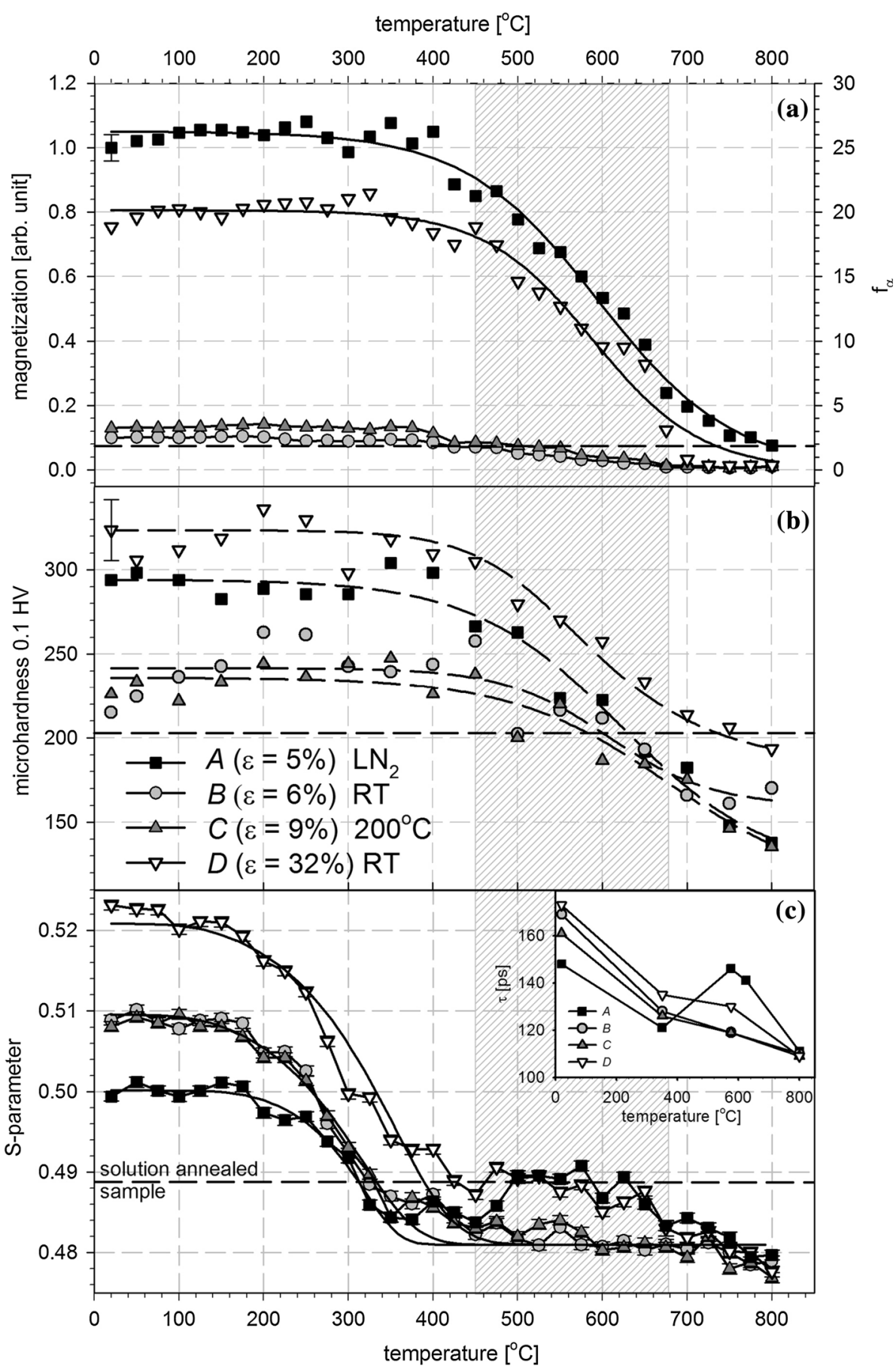

SSs occurs at temperatures about $100{ }^{\circ} \mathrm{C}$ higher than the martensite reversion temperature [22]. The microhardness dependence correlates with magnetization changes shown in Fig. 3a.

Doppler broadening and positron lifetime measurements

Figure $3 \mathrm{c}$ presents the results of DB measurements for isochronal annealing of the samples, i.e., the S-parameter dependence on the annealing temperature. The highest initial value of the S-parameter for the sample $D(\varepsilon=32 \%)$ indicates the highest defect concentration, and the lowest value of the S-parameter for the sample $A(\varepsilon=5 \%)$ indicates the lowest defect concentration. Thus, for these two samples the S-parameter behavior differs from the microhardness behavior, which indicates that the two measurement methods provide information on different microstructure-related properties. The values of the S-parameter for the samples $B \quad(\varepsilon=6 \%)$ and 
$C(\varepsilon=9 \%)$ do not differ within the experimental accuracy. Annealing up to $175^{\circ} \mathrm{C}$ does not change the $\mathrm{S}$-parameter values or causes only small decrease as it is for the sample $D(\varepsilon=32 \%)$. Decrease of the S-parameter with temperature starting at $200{ }^{\circ} \mathrm{C}$ indicates decrease of concentration of positron trapping defects. This type of behavior may be described, for example, by vacancy migration model, in which annealing of the deformed sample causes diffusion of vacancies to grain boundaries or other sinks where they annihilate [37]. The smooth solid lines in Fig. 3c are fitted to the experimental points using this model. They follow the experimental points up to the annealing temperature of $375{ }^{\circ} \mathrm{C}$. Above this temperature, the $\mathrm{S}$-parameter values are higher than those indicated by the model even for the samples with the low initial $\alpha^{\prime}$ martensite fraction, i.e., $B(\varepsilon=6 \%)$ and $C(\varepsilon=9 \%)$. For these samples, the S-parameter decrease becomes less steep. For the samples $A(\varepsilon=5 \%)$ deformed at $\mathrm{LN}_{2}$ temperature and $D(\varepsilon=32 \%)$ deformed at RT with the $\alpha^{\prime}$ martensite volume fractions 0.25 and 0.19 , behavior of the $\mathrm{S}$-parameter is different. The S-parameter increases and exhibits distinctly higher values in the temperature range between 450 and $650{ }^{\circ} \mathrm{C}$. For higher annealing temperatures, the S-parameter decreases and follows the values obtained for two other samples. The values of the vacancy migration energies obtained from the model for four samples studied, i.e., $0.51-0.54 \mathrm{eV}$, are relatively low in comparison to, e.g., $0.9 \mathrm{eV}$ obtained by Holzwarth et al. for $316 \mathrm{~L}$ SS for which deformation did not induce $\alpha^{\prime}$-martensite [38]. This confirms that the vacancy migration model does not describe well the S-parameter dependencies obtained for austenitic SS containing DIM because new defects are created during martensite reversion. Comparison of Fig. 3a, c shows that the region of elevated values of the S-parameter for the samples $A(\varepsilon=5 \%)$ and $D(\varepsilon=32 \%)$ coincides with the region of the magnetization decrease. This confirms that the increase of the S-parameter for the samples with higher amount of $\alpha^{\prime}$ martensite is caused by generation of crystal lattice open volume defects accompanying DIM reversion. The dashed line in Fig. 3c indicates the value of the S-parameter for the sample after the solution annealing. This value is higher than those for the samples at the end of the annealing procedure because the applied solution annealing and cooling in air did not remove all crystal lattice defects which localize positrons.

In order to specify the types of defects, the positron lifetime spectra were measured for the as-deformed samples and after annealing in a few selected temperatures. Only single positron lifetime was resolved in the spectra and it is treated as the mean positron lifetime. The mean positron lifetime versus annealing temperature is depicted in the insert in Fig. 3c. Difficulties in separation of lifetime components may be caused by competitive trapping of positrons in a family of defects giving lifetimes to close be isolated. For the as-deformed samples, the mean positron lifetimes are significantly higher than the bulk positron lifetime for $\alpha$-Fe, i.e., 108 ps [34]. However, they are lower than the lifetime of positron trapped in vacancies in $\alpha-\mathrm{Fe}$, i.e., 175 ps [50]. It is worth noticing that monovacancies induced in iron, for example, by electron irradiation migrate already at temperatures as low as $200 \mathrm{~K}$ [50]. The theoretical calculations of positron lifetimes for the fcc structure of $\mathrm{Fe}$ atoms give the values lower than that observed for $\alpha$-Fe, i.e., 99 ps for positron lifetime in bulk and $167 \mathrm{ps}$ for monovacancy [51]. But the presence of carbon atoms in the vicinity of monovacancy causes increase of the positron lifetime [51]. The obtained positron lifetimes can be compared to those observed in deformed iron and assigned to annihilation of positrons in dislocation-associated defects. They were found being close to $150 \mathrm{ps}$ [52], though the values of 142 and 165 ps were also reported [53]. It is commonly accepted that dislocation lines are shallow traps for positron. However, a positron diffusing along a dislocation core may be localized in deeper traps associated with the dislocation like jogs or vacancies bound in the strain field of the dislocation. Annihilation of positrons localized in such traps gives the lifetime lower than that characteristic for monovacancy. The presence of the alloying elements in steel may also influence positron lifetimes. The lifetimes calculated for vacancy-solute complexes for steel alloying elements (e.g., $\mathrm{V}-\mathrm{Cr}$ or $\mathrm{V}-\mathrm{Cu}$ ), i.e., $152-154$ ps are also lower than that for monovacancy in $\alpha \mathrm{Fe}$ [54].

The values of the mean positron lifetime higher than those for dislocation-associated defects may suggest that there is some contribution from positron annihilation in small vacancy clusters. For the samples after annealing at $350{ }^{\circ} \mathrm{C}$, the mean positron lifetime decreases, which is caused by annealing of defects. For the samples $A(\varepsilon=5 \%)$ and $D(\varepsilon=32 \%)$ after annealing at $575{ }^{\circ} \mathrm{C}$, the mean positron lifetime increases as does the $\mathrm{S}$-parameter. As expected, the changes of the mean positron lifetime follow the changes of the S-parameter, and the values of the mean positron lifetime after completing of the annealing procedure are close to the bulk value for $\alpha$-Fe.

For the sample $A$ ( $\varepsilon=5 \%$ ) deformed at $\mathrm{LN}_{2}$ temperature, two components in the positron lifetime spectra measured after annealing at $575{ }^{\circ} \mathrm{C}$ and additionally at $625{ }^{\circ} \mathrm{C}$ can be resolved. For the temperature of $575{ }^{\circ} \mathrm{C}$ they are as follows: $\tau_{1}=(128 \pm 3)$ ps with intensity $I_{1}=(93 \pm 1) \%$ and $\tau_{2}=(319 \pm 26)$ ps with intensity $I_{2}=(7 \pm 1) \%$; and for the temperature of $625^{\circ} \mathrm{C}$ they are: $\tau_{1}=(123 \pm 3) \mathrm{ps}$ with intensity $I_{1}=(91 \pm 2) \%$ and $\tau_{2}=(275 \pm 24) \mathrm{ps}$ with intensity $I_{2}=(9 \pm 2) \%$. Such values of positron lifetime in $\alpha-\mathrm{Fe}$ can be assigned to positrons annihilating in 
clusters of 6-9 vacancies according to calculations performed by Puska and Nieminen [55]. Further annealing causes disappearance of these vacancy clusters.

\section{Discussion}

Mechanical properties of deformed austenitic SS depend strongly on the amount of DIM. Mangomon and Thomas found that yield strength of 304 SS after different mechanical and thermo-mechanical treatment is linearly proportional to the amount of $\alpha^{\prime}$-martensite [56]. Takanishi and Shitani showed that the hardness of cold rolled 304 SS is proportional to $\alpha^{\prime}$-martensite amount [57]. They also found that the dislocation density in the $\alpha^{\prime}$ phase is close to saturated value even for low strain and increases only scarcely with strain whereas the dislocation density in austenite increases significantly with increasing strain and then saturates. Taking into account only the $\alpha^{\prime}$-martensite amount, the microhardness for the as-deformed sample $A(\varepsilon=5 \%)$ should be higher than that for the sample $D(\varepsilon=32 \%)$ by virtue of the higher amount of $\alpha^{\prime}$-martensite. This indicates that for the sample $D(\varepsilon=32 \%)$, the significant contribution to microhardness comes from dislocation density in austenite grains, which is confirmed by the higher values of the S-parameter and the mean positron lifetime caused mainly by annihilation of positron trapped in dislocation-associated defects.

Mechanisms of reversion from deformation-induced martensite to austenite depend on the chemical composition of steel and annealing conditions. According to Tomimura et al. who studied the reversion mechanisms in cold rolled 304 steel, in order to obtain the critical driving force for martensitic shear reversion in $18 \mathrm{Cr}-9 \mathrm{Ni}$ steel, the steel should be heated to a temperature above $750{ }^{\circ} \mathrm{C}$ [58]. However, the diffusional reversion can easily occur at lower temperatures. Diffusional reversion mechanism is characterized by random nucleation of the austenite grains inside the martensite laths and equiaxed growth. The grain growth leads to increase in the austenite amount, and most of the grains are bounded by large angle boundaries. If the reversion is not complete, remained tempered martensite grains are present within austenite grains. Since the annealing of our samples started at low temperatures, the diffusional mechanism of martensite reversion should be taken into account. Then, the vacancy clusters which were detected by positron lifetime measurements can be the result of volume contraction accompanying bcc/fcc change, and they can form at martensite-austenite interfaces in the course of the transformation. The value of the first lifetime component higher than the bulk value for $\alpha-\mathrm{Fe}$ indicates that other defects such as dislocations and dislocation-associated defects are also present in the sample.
There is a difference in the behavior of the samples $A(\varepsilon=5 \%)$ and $D(\varepsilon=32 \%)$. The lifetime component coming from annihilation in vacancy clusters is distinctive for the sample $A(\varepsilon=5 \%)$ deformed at $\mathrm{LN}_{2}$ temperature with initial $f_{\alpha^{\prime}}=0.25$. In spite of a similar behavior of the S-parameter in the temperature range between 450 and $650{ }^{\circ} \mathrm{C}$, the mean positron lifetime measured at $575^{\circ} \mathrm{C}$ for the sample $D(\varepsilon=32 \%)$ deformed at RT with initial $f_{\alpha^{\prime}}=0.19$ is slightly lower than that for the sample $A(\varepsilon=5 \%)$. The analysis of this positron lifetime spectrum with the value of the second component fixed at $300 \mathrm{ps}$ gives its intensity lower than $3 \%$. Then, the vacancy clusters if present in the sample $D(\varepsilon=32 \%)$ are smaller and/or have lower concentration than for the sample $A(\varepsilon=5 \%)$. This may be caused by a lower initial fraction of martensite or the influence of higher initial concentration of dislocations on vacancy cluster formation.

There should be considered also another phenomenon in SSs which can cause an increase of the S-parameter or mean positron lifetime, i.e., precipitation of carbides [37]. Several studies reported the increase of the S-parameter or mean positron lifetime values in ferritic/martensitic steels which could be attributed to the nucleation and growth of metal carbide precipitates mainly $\mathrm{M}_{23} \mathrm{C}_{6}$ at temperatures above $500{ }^{\circ} \mathrm{C}$. In that case, the positron trapping sites were expected to be precipitate matrix interfaces [42]. The subsequent decrease of these parameters with a minimum at $800{ }^{\circ} \mathrm{C}$ was explained as caused by coarsening of the precipitates and decrease of positron trapping. Other authors studied cold worked Ti-modified D9 $(15 \mathrm{Ni}-15 \mathrm{Cr})$ austenitic SS and observed increase of the S-parameter or mean positron lifetime for the temperatures higher than $530{ }^{\circ} \mathrm{C}$ which they attributed to positron trapping at precipitate-matrix interfaces of $\mathrm{TiC}$ precipitates in austenitic matrix [59-61]. The increase was not observed for the Tifree FeCrNi model alloy. However, DIM was not considered in those studies.

Chromium carbide precipitation in 304 stainless steels is governed by the thermodynamics of carbon concentration and kinetics of chromium diffusion. The increasing carbon content decreases the sensitization time. This phenomenon involves development of carbide precipitates $\left(\mathrm{Cr}_{23} \mathrm{C}_{6}\right)$ in the grain boundary region in the temperature range from 480 to $850{ }^{\circ} \mathrm{C}$ resulting in chromium depletion near the grain boundary; as a result, grain boundary region is prone to preferential intergranular corrosion [62-64]. The SS studied in our case has relatively low content of carbon, i.e., $0.023 \mathrm{wt} \%$ and the total annealing time for temperatures between 450 and $650{ }^{\circ} \mathrm{C}$ was $11 \mathrm{~h}$. For $304 \mathrm{SS}$ with similar carbon content aged for $50 \mathrm{~h}$ at $670{ }^{\circ} \mathrm{C}$, Trillo and Murr found that a few small carbides precipitations were nucleated on high-angle grain boundaries [65]. However, not only carbon content but also factors connected to 
chromium diffusion such as strain and strain state influence chromium carbide precipitation [66]. It is known that cold working promotes the formation of both the carbides and intermetallic phases and deformation reduces the time required for sensitization [66-68]. The effect is more pronounced in the $\alpha^{\prime}$-martensite containing $304 \mathrm{SS}$ than in the type $316 \mathrm{SS}$, especially at temperatures below $600{ }^{\circ} \mathrm{C}$ [62].

In the light of all this, the influence of chromium carbon precipitates on the observed increase of the S-parameter in our experiment for the samples $A \quad(\varepsilon=5 \%)$ and $D(\varepsilon=32 \%)$ with higher amount of $\alpha^{\prime}$-martensite cannot be entirely excluded. Nonetheless, our additional X-ray diffraction measurement using $\mathrm{Co} K_{\alpha}$ radiation for the samples after annealing procedure did not reveal significant differences which could be ascribed to different amounts of chromium carbide precipitates. The increase of microhardness accompanying the increase of the S-parameter indicating carbides precipitation was not observed.

\section{Conclusions}

PAS studies were carried out on austenitic SS 1.4301 (EN) deformed in tension at different temperatures to investigate the microstructural changes as a function of heat treatment. The temperature dependence of the annihilation line shape parameter, i.e., the S-parameter shows the gradual annealing of the defects induced by deformation. However, the increase of the $\mathrm{S}$-parameter in the temperature range between 450 and $650{ }^{\circ} \mathrm{C}$ for two samples with higher volume fraction of deformation-induced $\alpha^{\prime}$-martensite, i.e., 0.19 and 0.25 , indicates generation of new lattice defects, which trap positrons. This temperature range coincides with the temperature range of $\alpha^{\prime}$-martensite reversion which was confirmed by magnetic properties measurements and indicated by Vickers microhardness decrease.

Positron lifetime measurements for the sample deformed to $5 \%$ at $\mathrm{LN}_{2}$ temperature with the initial $\alpha^{\prime}$-martensite fraction $f_{\alpha^{\prime}}=0.25$ revealed the presence of large vacancy clusters comprising 6-9 vacancies in this temperature range. Their presence can be caused by volume contraction accompanying bcc/fcc change. Volume excess may contribute to the vacancy cluster formation at martensiteaustenite interfaces in the course of the transformation. However, the analysis of the positron lifetime spectrum measured for the sample deformed to $32 \%$ at RT with initial $f_{\alpha^{\prime}}=0.19$ indicates that vacancy clusters if present have a significantly lower concentration. This may be caused by the lower initial fraction of martensite or the influence of higher initial concentration of dislocations resulting from higher deformation level. In spite of the low carbon content in the SS investigated, the influence of chromium carbide precipitation on grain boundaries on the S-parameter increase cannot be excluded which is connected to the fact that cold working and $\alpha^{\prime}$-martensite presence promote formation of carbides.

Open Access This article is distributed under the terms of the Creative Commons Attribution License which permits any use, distribution, and reproduction in any medium, provided the original author(s) and the source are credited.

\section{References}

1. Maksimova OP (1999) Martensite transformations: history and laws. Met Sci Heat Treat 41:322-339

2. Mangonon PL Jr, Thomas G (1970) The martensite phases in 304 stainless steel. Metall Mater Trans 1:1577-1586

3. Tavares SSM, Da Silva MR, Neto JM, Miraglia S, Fruchart D (2002) Ferromagnetic properties of cold rolled AISI 304L steel. J Magn Magn Mat. 242-245:1391-1394

4. Mumtaz K, Takahashi S, Echigoya J, Kamada Y, Zhang LF, Kikuchi H, Ara K, Sato M (2004) Magnetic measurements of martensitic transformation in austenitic stainless steel after room temperature rolling. J Mater Sci 39:85-97. doi:10.1023/B:JMSC. 0000007731.38154.e1

5. Mumtaz K, Takahashi S, Echigoya J, Kamada Y, Zhang LF, Kikuchi H, Ara K, Sato M (2004) Magnetic measurements of the reverse martensite to austenite transformation in a rolled austenitic stainless steel. J Mater Sci 39:1997-2010. doi:10.1023/B: JMSC.0000017761.64839.fc

6. Seetharaman V, Krishnan R (1981) Influence of the martensitic transformation on the deformation behavior of an AISI 316 stainless steel at low temperatures. J Mater Sci 16:523-530. doi:10.1007/BF00738646

7. Fukuda T, Kakeshita T, Kindo K (2006) Effect of high magnetic field and uniaxial stress at cryogenic temperatures on phase stability of some austenitic stainless steels. Mater Sci Eng A 438-440:212-217

8. Das A, Sivaprasad S, Ghosh M, Chakraborti PC, Tarafder S (2008) Morphologies and characteristics of deformation induced martensite during tensile deformation of $304 \mathrm{LN}_{2}$ stainless steel. Mater Sci Eng A 486:283-286

9. Marshall P (1984) Austenitic stainless steels, microstructure and properties. Elsevier Applied Science Publishers, London

10. de Abreua HKG, de Carvalho SS, de Lima NP, dos Santos R, Freire VN, de Oliveira Maria, Silva P, Tavares SSM (2007) Deformation induced martensite in an AISI 301LN stainless steel: Characterization and influence on pitting corrosion resistance. Mater Res 10:359-366

11. Mirzadeh H, Najafizadeh A (2008) Correlation between processing parameters and strain-induced martensitic transformation in cold worked AISI 301 stainless steel. Mater Character 59:1650-1654

12. Talonen J, Hänninen $H$ (2007) Formation of shear bands and strain-induced martensite during plastic deformation of metastable austenitic stainless steels. Acta Mater 55:6108-6118

13. Herrera C, Plaut RL, Padilha AF (2007) Microstructural refinement during annealing of plastically deformed austenitic stainless steels. Mater Sci Forum 550:423-428

14. Zackay VF, Parker ER, Fahr D, Busch R (1967) The enhancement of ductility in high-strength steels. Trans ASM 60:252-259

15. Berrahmoune MR, Berveiller S, Inal K, Patoor E (2006) Delayed cracking in 301LN austenitic steel after deep drawing: Martensitic transformation and residual stress analysis. Mater Sci Eng A 438-440:262-266 
16. Shindo Y, Takeda T, Suzuki M, Narita F (2009) Fatigue crack growth behavior of metastable austenitic stainless steel in cryogenic high magnetic field environments. Metal Mat Trans A 40:1863-1867

17. Chunchun X, Gang H (2004) Effect of deformation-induced martensite on the pit propagation behavior of 304 stainless steel. Anti-Corros Methods Mater 51:381-388

18. Man J, Obrtlik K, Petrenec M, Brean P, Smaga M, Weidner A, Dluhos J, Kruml T, Biermann H, Eifler D, Polak J (2011) Stability of austenitic 316L steel against martensite formation during cyclic straining. Proc Eng 10:1279-1284

19. Jha AK, Siva Kumar D, Sreekumar K, Sinha PP (2012) Effect of martensite transformation on toughness of $0.12 \mathrm{C}-0.5 \mathrm{Ti}-9 \mathrm{Ni}-$ $18 \mathrm{Cr}$ stainless steel. J Metal Eng 1:70-74

20. Lee SH, Choi JY, Nam WJ (2009) Hardening behavior of a 304 stainless steel containing deformation-induced martensite during static strain ageing. Mater Trans 50:926-929

21. Guy KB, Butler EP, West DRF (1983) Metal Sci 17:167

22. Marins LFM, Plaut RL, Padilha AF (1998) Effect of carbon on the cold-worked state and annealing of two $18 \mathrm{wt} \% \mathrm{Cr}-8 \mathrm{wt} \% \mathrm{Ni}$ austenitic stainless steels behavior. ISIJ Int 38:572-579

23. Tavares SSM, Fruchardt D, Miraglia S (2000) A magnetic study of the reversion of martensite \& \#x03B1;' in a 304 stainless steel. J Alloys Compd 307:311-317

24. Kurdyumov GV, Khandros LG (1949) On the thermoelastic equilibrium in martensitic transformation. Dokl Akad Nauk SSSR 66:211-214

25. Smith H, West DRF (1973) The reversion of martensite to austenite in certain stainless steels. J Mater Sci 8:1413-1420. doi:10. 1007/BF00551664

26. Breedis JF (1966) Martensite reversion in stainless steel. Trans Met Soc AIME 236:218-219

27. Kessler H, Pitsch W (1967) On the nature of the martensite to austenite reverse transformation. Acta Metall 15:401-405

28. Di Schino A, Salvatori I, Kenny JM (2002) Effects of martensite formation and austenite reversion on grain refining of AISI 304 stainless steel. J Mater Sci 37:4561-4565. doi:10.1023/A: 1020631912685

29. Rajasekhara S, Karjalainen LP, Kyröläinen A, Ferreira PJ (2010) Microstructure evolution in nano/submicron grained AISI 301LN stainless steel. Mat Sci Eng A 527:1986-1996

30. Krause-Rehberg R, Leipner HS (1999) Positron annihilation in semiconductors, vol 127., Solid-State SciencesSpringer, Berlin

31. Schaaff P, Holzwarth U (2005) Nondestructive detection of fatigue damage in austenitic stainless steel by positron annihilation. J Mater Sci 40:6157-6168. doi:10.1007/s10853-005-3163-5

32. Barbieri A, Hansen-Ilzhofer S, Ilzhofer A, Holzwarth U (2000) Nondestructive positron-lifetime measurements during fatigue of austenitic stainless steel using a mobile positron beam. Appl Phys Let 77:1911-1913

33. Kawaguchi Y, Nakamura N, Yusa S (2002) Non-destructive evaluation of fatigue damage in type 316 stainless steel using positron annihilation lineshape analysis. Mater Trans 43:727-734

34. Dryzek J, Horodek P, Wróbel M (2012) Use of positron annihilation measurements to detect the defect beneath worn surface of stainless steel $1.4301(\mathrm{EN})$ under dry sliding condition. Wear 294-295:264-269

35. Horodek P, Dryzek J, Wróbel M (2012) Positron annihilation study of defects induced by various cutting methods in stainless steel grade 304. Tribol Lett 45:341-347

36. Zaleski R, Zaleski K (2006) Positron annihilation in steel burnished by vibratory shot peening. Acta Phys Polon A 110: 739-746

37. Dryzek J, Wesseling C, Dryzek E, Cleff B (1994) Migration of vacancies in stainless steel measured by positron annihilation. Mater Lett 21:209-214
38. Holzwarth U, Barbieri A, Hansen-Ilzhöfer S, Schaaff P, Haaks M (2001) Positron annihilation studies on the migration of deformation induced vacancies in stainless steel AISI 316L. Appl Phys A 73:467-475

39. Matter H, Winter J, Triftshäuser W (1979) Phase transformations and vacancy formation energies of transition metals by positron annihilation. Appl Phys 20:135-140

40. Dryzek E, Kuriplach J, Dryzek J (1998) Study of the $\mathrm{Mg}-\mathrm{Cd}$ system by positron annihilation methods. J Phys 10:6573-6584

41. Slugen V, Kögel G, Sperr P, Triftshäuser W (2002) Investigation of defect distributions in neutron-irradiated and thermally treated reactor steels by positron annihilation. Appl Surf Sci 194: $150-154$

42. Hari Babu S, Amarendra G, Rajaraman R, Sundar CS (2013) Microstructural characterization of ferritic/martensitic steels by positron annihilation spectroscopy. J Phys. doi:10.1088/17426596/443/1/012010

43. Dryzek E, Sarnek M, Siemek K (2013) Annealing behavior of plastically deformed stainless steel 1.4307 studied by positron annihilation methods. Nukleonika 58:213-217

44. Dryzek E, Sarnek M (2014) Reverse transformation of deformation induced martensite in austenitic stainless steel studied by positron annihilation. Acta Phys Polon A 125:710-713

45. Davis R (1995) Determining the magnetic properties of $1 \mathrm{~kg}$ mass standards. J Res Natl Inst Stand Technol 100:209-225

46. Davis R, Gläser M (2003) Magnetic properties of weights, their measurements and magnetic interactions between weights and balances. Metrologia 40:339-355

47. Kansy J (1996) Microcomputer program for analysis of positron annihilation lifetime spectra. Nucl Instr Methods A 374:235-244

48. Bonarski JT, Wróbel M, Pawlik K (2000) Quantitative phase analysis of duplex stainless steel using incomplete pole figures. Mater Sci Technol 16:657-662

49. Bonarski J, Wróbel M, Pawlik K (1991) Improvement of quantitative phase analysis of textured materials. Scr Metal Mater 25:1401-1404

50. Vehanen A, Hautojärvi P, Johanson J, Yli-Kauppilla J, Moser P (1982) Vacancies and carbon impurities in $\alpha$ - iron: electron irradiation. Phys Rev B 25:762-780

51. Asoka-Kumar P, Hartley JH, Howell RH, Sterne PA, Akers D, Shah V, Denison A (2002) Direct observation of carbon-decorated defects in fatigued type 304 stainless steel using positron annihilation spectroscopy. Acta Mater 50:1761-1770

52. Hidalgo H, Donzález-Doncel G, Linderoth S, San Juan J (1992) Structure of dislocations in $\mathrm{Al}$ and $\mathrm{Fe}$ as studied by positronannihilation spectroscopy. Phys Rev B 45:7017-7021

53. Park YK, Waber JT, Meshii M, Snead CL Jr, Park CG (1986) Dislocation studies on deformed single crystals of high-purity iron using positron annihilation: determination of dislocation densities. Phys Rev B 34:823-839

54. Kuriplach J, Melikhova O, Domain C, Becquart CS, Kulikov D, Malerba L, Hou M, Almazouzi A, Duque CA, Morales AL (2006) Vacancy-solute complexes and their clusters in iron. Appl Surf Sci 252:3303-3308

55. Puska MJ, Nieminen RM (1983) Defect spectroscopy with positrons: a general calculational method. J Phys F 13:333-346

56. Mangonon PL, Thomas G (1970) Structure and properties of thermal-mechanically treated 304 stainless steel. Metall Trans $1: 1587-1594$

57. Shintani T, Murata Y (2011) Evaluation of the dislocation density and dislocation character in cold rolled Type 304 steel determined by profile analysis of X-ray diffraction. Acta Mater 59:4314-4322

58. Tomimura K, Takaki S, Tokunaga Y (1991) Reversion mechanism from deformation induced martensite to austenite in metastable austenitic stainless steels. ISIJ Int 31:1431-1437 
59. Rajaraman R, Gopalan P, Viswanathan B, Venkadesan S (1994) A positron annihilation study of $\mathrm{TiC}$ precipitation in plastically deformed austenitic stainless steel. J Nucl Mater 217:325-328

60. Arunkumar J, Abhaya S, Rajaraman R, Amarendra G, Nair KGM, Sundar CS, Baldev Raj (2009) Defect recovery in proton irradiated Ti-modified stainless steel probed by positron annihilation. J Nucl Mater 384:245-248

61. Rajaraman R, Amarendra G, Sundar CS (2009) Defect evolution in steels: Insights from positron studies. Phys Status Solidi C 6:2285-2290

62. Briant CL, Ritter AM (1980) The effects of deformation induced martensite on the sensitization of austenitic stainless steels. Metall Mater Trans A 11:2009-2017

63. Raghuvir Singh, Ravikumar B, Dey PKKA, Chattoraj I (2003) The effects of cold working on sensitization and intergranular corrosion behavior of AISI 304 stainless steel. Metal Mat Trans A 34:2441-2447

64. Alvarez CJ, Almanza E, Murr LE (2005) Evaluation of the sensitization process in 304 stainless steel strained $50 \%$ by coldrolling. J Mater Sci 40:2965-2969
65. Trillo EA, Murr LE (1998) A TEM investigation of M23C6 carbide precipitation behaviour on varying grain boundary misorientations in 304 stainless steels. J Mater Sci 33:1263-1271. doi:10.1023/A:1004390029071

66. Trillo EA, Beltran R, Maldonado JG, Romero RJ, Murr LE, Fisher WW, Advani AH (1995) Combined effects of deformation (strain and strain state), grain size, and carbon content on carbide precipitation and corrosion sensitization in 304 stainless steel. Mater Char 35:99-112

67. Tsubakino H, Yamamoto A, Yamada T, Liu L, Terasawa M, Nakahigashi S, Harada H (2004) Effect of cold-rolling on precipitation phenomena in sensitized type $316 \mathrm{~L}$ and $340 \mathrm{~L} \mathrm{Au}-$ stenitic Stainless Steels. Trans Mater Heat Treat 25:217-222

68. Oh YJ, Hong JH (2000) Nitrogen effect on precipitation and sensitization in cold-worked Type 316L(N) stainless steels. Nucl Mater 278:242-250 